\title{
SpART: Bringing People Together Through Sport and Art
}

\author{
Pierre Leichner \\ Thompson Community Center, Richmond, Canada
}

\begin{abstract}
SpART was a one-year part time artist residency whose goal was to engage members of a recreational community center in making artistic expressions of the sports they participated in Over 200 participants actively engaged and over a thousand members of the public saw and watched their art works. Overall, participation was enthusiastic. The project demonstrated how art could be introduced in daily operations of a sport-focused community center. A video of sporting memories highlighted the benefits of sport in building community, friendships and maintaining health. Space and time were limitations.
\end{abstract}

Keywords: community engagement, artistic expression

\section{Introduction}

Sport and art have always been intertwined, be it just with the artistic representation of sport. Starting in the 1960's, changes in both have led to a strengthening of that relationship such that their borders are now blurred. Matti Tainio in his book, Parallel Worlds. Art and Sport in Contemporary Culture (Tainio, 2015), analyses this relationship meticulously and concludes that: "While art and sport have been related through their connection in the emergence of modern European culture, currently there are even more reasons to see them as a parallel practices” (Tainio, 2015, p. 289).

One notable change has been the shift away in art and sport from being the domain reserved to the trained artist or athlete, to recognizing the beneficial value to the health of all individuals and their communities. The level of participation of individuals of all ages has increased exponentially in the last decades. This has been reflected in most Canadian community centers, as they now offer opportunities for involvement in both art and sport under one roof.

Traditionally, art and sport have been viewed as having similarities (Cordner, 1988) or as separate (Kosiewicz, 2014), even being opposites by some (Best, 1980). However, I believe that they share, in their essence, the uniquely human instinct to make stories in order to understand our reality. Of course, there are obvious differences in the means and the settings used by the individuals and the audiences involved, but I believe that the aesthetic feelings obtained after playing in or watching a well-performed game or art performance are akin.

It was with the goal to introduce artistic activities in the various sporting classes offered at the Thompson Community Center for recreation and sport in Richmond, Canada that a one-year part-time artist residency was implemented. The following is a description of the project's process and outcomes as I experienced them. The

\footnotetext{
Acknowledgement: The author wishes to thank the support of the center staff in particular Renata Turryck, Derrick Bloomfield, and Sharlene Singh. The Public Arts Program of the City of Richmond, BC, Canada funded this project.

Pierre Leichner, 2017Artist in Residence, Thompson Community Centre, Richmond, Canada.
} 
objective of this report is to facilitate the implementation of similar projects in the other centers. Its' successes and areas for improvement are discussed. Recommendations are made in conclusion.

\section{The SpART Project}

In 2016, an artist call was made by the Richmond City program to select an artist in residence for the Thompson Recreation Community Center. The sum of $\$ 15,000$ was the fee allotted to the artist for a year. This was to include any materials or other fees spent by the artist over the year.

They were expected to give the equivalent of a couple days per week on site. Three artists' proposals were received and I was selected after meeting the selection committee. A meeting was then held with the city public arts manager and the TCC administrators to work out the framework and requirements for the project. I am an interdisciplinary artist with several years of experience participating in socially engaged projects involving all ages from the community at large to specific groups (Leichner, 2019). I believe that art is necessary for the wellbeing of individuals and their communities.

There were two major objectives stated in 2017. Firstly, it was to have participants of all ages enrolled in various physical activities listed in the community center program make art that relates to the sport they engaged in, thus exploring the artistic components of that sport. Secondly, it was to show this work to the public, thus demonstrating the many ways art and sport overlap. A collaborative participation approach (Helguera, 2011) was to be used whenever feasible. This approach in socially engaged art practice (Leichner, Lagarde, \& Lemaire, 2014) situates the artist more as a mentor or guide to the participants and less as the expert director in the creation of the artwork. Hence, it would be important to engage the instructors and participants from the onset in creating the work. Projects would emerge after a period of observation and were to be planned with their input. The administrative staff of the center was to provide the necessary in-house promotion and social media promotion. They would also facilitate the introduction of the artist to the instructors. They would also show the videos on the internal television screens.

A permanent information board and appropriate storage space would be provided for the year.

Quarterly reports were to be submitted to list outcomes to date and for payment.

Signed releases from adults and parents for photographs and/or videos would be obtained for each project when required. For consent of the documentation of participation in larger public events, a poster sign indicating the presence of city photographers beside the event would suffice.

SpART was to run on three tracts: one-time events, time limited projects, and longer-term projects.

\section{Outcomes}

\section{Interactive Information Board and Installations}

The first step was to create an interactive information board in the center's lounge area that was dedicated to SpART throughout the year.

At various times it displayed photographs of activities, drawings made by children and interactive questions. These were used to encourage members to think about their relationship with sports. They included: What is your favorite sport to play? What is your favourite sport to watch? What do you like most about it? Who is your favorite player? What do you like most about them? (Leichner, 2017)

The Art Gallery in the main corridor of the center was installed with works that had been created on three occasions during the year. 
The abstract paintings were installed in the gym and the game room throughout the year.

Finally, the art objects made by the seniors were installed in the games room wall and spaces during the year.

One-time projects occurred specifically on days that brought a larger public audience to the center. Participation across all ages was the focus. Three events were identified at the onset and two came up during the year. These are listed below. Figures 1 and 2 show participants playing and making Abstract Bocce Ball paintings and the paintings as they were displayed in the gym during the rest of the year.

Table 1

One-Time SpART Projects

\begin{tabular}{llll}
\hline Events & Artwork & $\begin{array}{l}\text { Approximate number of } \\
\text { participants }\end{array}$ & $\begin{array}{l}\text { Approximate number of } \\
\text { viewers }\end{array}$ \\
\hline Family Day & $\begin{array}{l}\text { Abstract Bocce Ball } \\
\text { 5 paintings }\end{array}$ & 50 & 500 \\
Community Picnic & $\begin{array}{l}\text { Video time lapse } \\
\text { Run and Paint } \\
\text { Coloring Sporting Animals }\end{array}$ & 60 & 1,000 \\
Children and Families Day & T shirt Tie Dye Workshop & 15 & 500 \\
Youth BBQ & T shirt Tie Dye Workshop & 30 & - \\
Youth and Family Pride Day & & 60 \\
\hline
\end{tabular}

Source: Pierre Leichner, 2018.

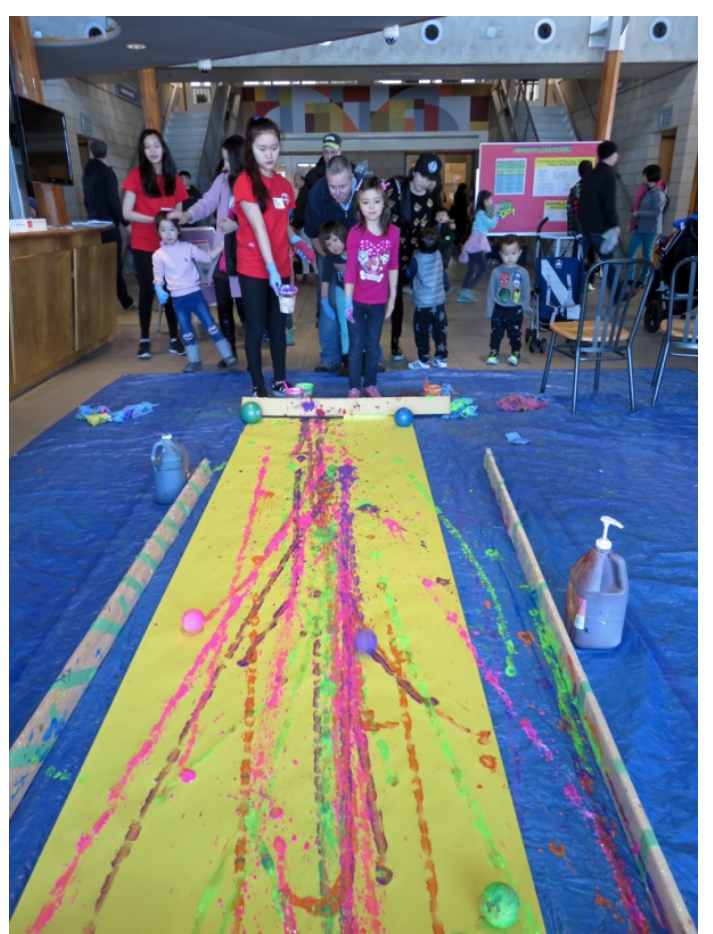

Figure 1. Family Day participants making Abstract Bocce Ball paintings. Pierre Leichner, 2017. 


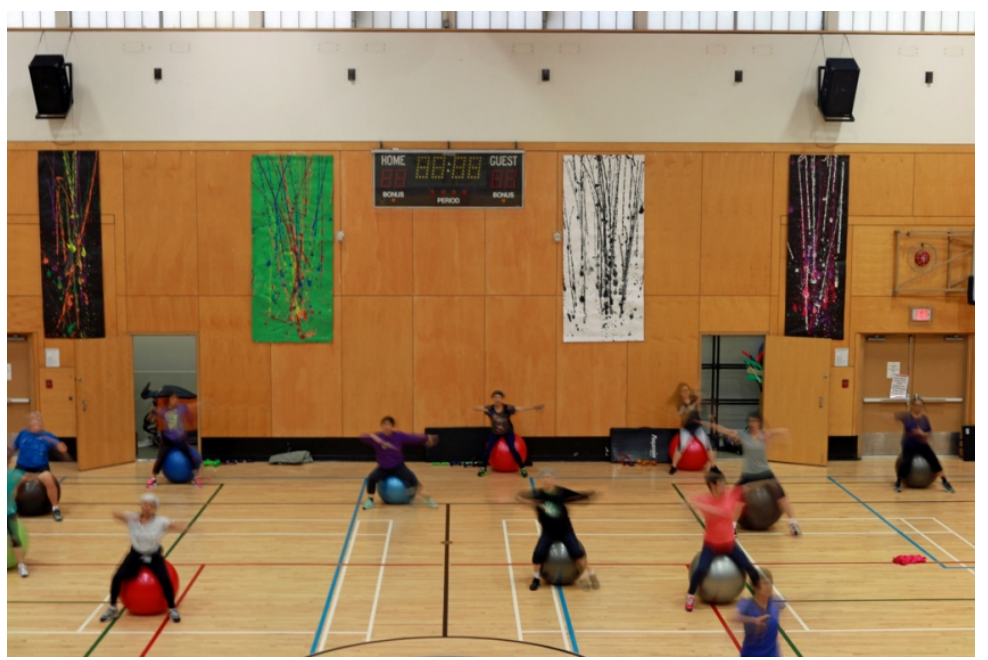

Figure 2. Abstract Bocce Ball paintings on display in gym. Pierre Leichner, 2017.

Time limited projects focused sequentially on specific sporting activities. The principle was to complete a project within a couple months and to exhibit it. The center's program ran on a quarterly seasonal cycle. Before each began, the artist and the staff selected the classes or groups that would be contacted. These are listed below. Consent forms in Chinese and English were handed out to parents. Figures 3 and 4 are examples of the motion and light photographs that were taken. Photographs were displayed on the SpART information board and also in the entrance hall of the center. The following groups' projects were completed:

Table 2

Time Limited SpART Projects

\begin{tabular}{|c|c|c|c|}
\hline & Artwork & $\begin{array}{l}\text { Approximate number of } \\
\text { participants }\end{array}$ & $\begin{array}{l}\text { Approximate number of } \\
\text { viewers }\end{array}$ \\
\hline Basketball Children Class & $\begin{array}{l}2 \text { videos } \\
\text { Electric Fence Game \#1 and } 2\end{array}$ & 20 & 500 \\
\hline Volleyball Children Class & $\begin{array}{l}\text { One abstract painting Gaga Ball Game } \\
2 \text { videos }\end{array}$ & 15 & 500 \\
\hline Adult Fitness Classes & $\begin{array}{l}\text { Can You Feel It and We Are Family } \\
\text { Motion Trail Photographs } \\
\text { video Soccer } 101\end{array}$ & 25 & 500 \\
\hline Children Soccer & $\begin{array}{l}\text { Motion Trail Photographs } \\
2 \text { abstract paintings }\end{array}$ & 20 & 500 \\
\hline Rompers Pre-school & video Tree Weaving & 15 & 100 \\
\hline Zumba Seniors & $\begin{array}{l}\text { video Zumba Gold } \\
\text { Motion Trail Photographs }\end{array}$ & 10 & 100 \\
\hline Seniors Fitness & video Call Me Maybe & 20 & 500 \\
\hline Children Taekwondo & $\begin{array}{l}\text { video Jon Gyung/Respect } \\
\text { Motion and Light Trails Photographs }\end{array}$ & 40 & 100 \\
\hline Adult Indoor Soccer & Motion Trails Photographs & 20 & 500 \\
\hline
\end{tabular}

Source: Pierre Leichner, 2018. 


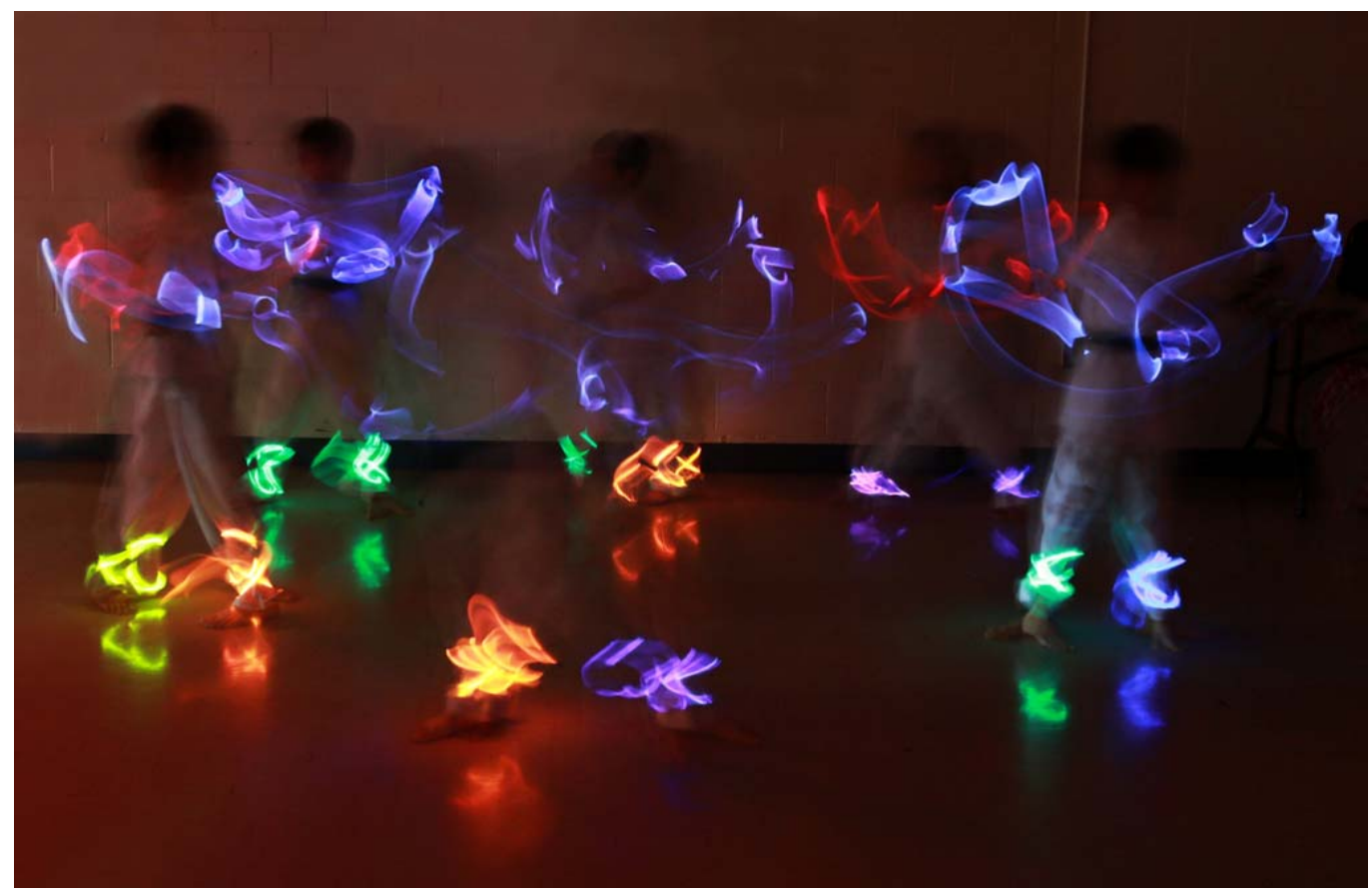

Figure 3. Children Taekwondo Class. Pierre Leichner, 2017.

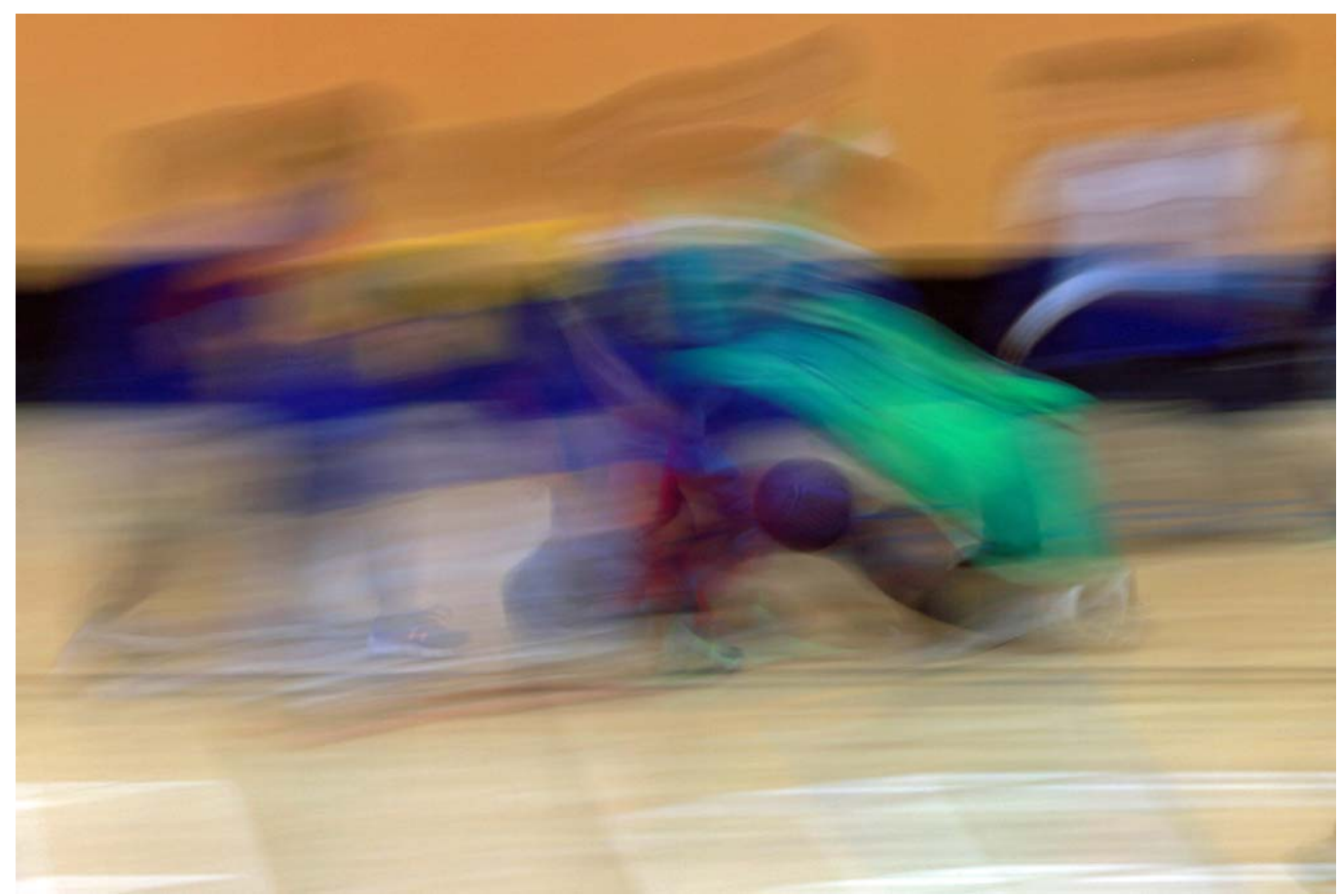

Figure 4. Adult Fitness Class. Pierre Leichner, 2017.

Longer-term projects ran throughout the residency.

Sporting memories. Video interviews were obtained in different settings and times from members and participants about their favorite sporting memories; the positive and negative aspects of participating in sports. All signed informed consent forms. 
I filmed 29 interviews. All the stories shared were meaningful. I was impressed by the positive aspects these athletes shared; learning about teamwork, creating friendships and a connection to the community, benefiting physical and mental health, being a stress relief, and the emotional highs and lows of watching and participating. As far as negatives, injuries came up very often and dealing with poor sportsmanship only a few times. A shorter 18 minutes video was edited for viewing. However, all the interviews were edited, organized and available in longer 38 minutes video as well. (Leichner, 2017)

Memories of sporting events were also the focus of a workshop for seniors at the Activate 55+ Richmond Fair. With collaboration from a graphic recorder, a poster was produced. The memories highlighted how sport brought the family together. The inappropriate aggressive behaviors of some athletes and spectators were also mentioned. The poster was displayed on the information board for one month.

Sporting creations by seniors. Four, two hours workshops were organized with the senior's group to work on transforming sport equipment. Used table tennis, badminton and tennis racquets, balls from soccer, basketball football, and table tennis were provided. Various art materials were brought to make art with these objects. The seniors then installed their works in the game room where these stayed on display throughout the year. Over 40 actively participated and hundreds of visitors and community center members of all ages saw their work, as the game room was also a multipurpose space.

\section{Artist Talk and Presentations at International Conferences}

An artist talk was given at the center on participative theater in March.

A preliminary report on the project was presented at the International Conference Sports and Society in London England in June, and a final report on SpART was presented at the Arts in Society Conference at Emily Carr University in June 2018.

\section{Discussion}

This report is based on my personal observations and descriptions of the activities. It is limited by the fact that there was little formal evaluation from the participants other than anecdotal. This was in part due to the reluctance from the administrative recreational staff to introduce questionnaires to registrants, the explorative nature of the variety of activities developed, and the range of ages of the participants. The number of participants, the range of their ages, the variety of activities, and the number of viewers speak to their successful implementation. As an inaugural project, this report does not address any longer-term outcomes.

While sport and physical activity has been the subject for artists since antiquity, recent social cultural changes have brought them closer and the border between them has been fraying (Tainio, 2015, p. 285). I have experienced over the past decade the shift to community participation and the increased emphasis on the experience both in art and sport. This has led to increased calls for socially engaged art projects in communal public spaces. Both are being seen as opportunities for creative and personal development. Both can be examined as cultural practices. They are continuously evolving their own regulating systems, performance criteria and values including aesthetic judgments. Tanio suggest that if one views aesthetics as a form of embodied/sensuous experience, the physical activity in sport, both for the participant and the spectator, can develop sensory awareness, a connection to the environment and be enjoyable. "Contemporary recreational sport has moved its emphasis from measurable achievements toward (aesthetic) experience” (Tanio, 2015, p. 207). 
There has also been a growing awareness in contemporary art of the need to reconnect with the general public. This has given rise to an increase in socially engaged projects and a move away from traditional gallery and museum settings to various sites of human activity including hospitals, offices, and community centers. Significant research studies are revealing the beneficial effects of engaging in all forms of art on individuals and their community. This work has been reviewed and summarized in the National Organization for Arts in Health White Paper entitled: “Arts, Health, and Well Being in America” (National Organization for Arts in Health, 2017).

These two concomitant trends have opened sport up to the process of artification. This new concept refers to the situations when artistic aspects are found in activities previously not linked to art. In particular, I have noted the works of Matti Tainio using running as the subject of art and the means of making art. This project culminated in a multi-media exhibition What I Think When I Think About Running shown at the Sport Museum of Finland in Helsinki in 2012. Examples included: a series of maps showing the running paths he followed in several cities, while attempting to write out the cities' name in the chosen path, thus combining art making and running and transforming marathon running shoes into precious gold objects (Tainio, 2015, pp. 219-249). Artists that use sporting activities to express socio-political issues also influenced my practice. In 1991 Maurizio Cattelan created a soccer team from black immigrants in Italy called Southern Suppliers (Bishop, 2009). Another example is the art duo Marriage (Math Bass and Wu Ingrid Tsang) whose short video Soccer 2004 shows two players dressed in satin body suits practicing soccer moves (Doyle, 2018). The work questions the sports relationship to masculinity and creates its own queer vision of fitness and performance.

Bringing an art residency into a recreational center demonstrated that community athletes of all ages are open to exploring the artistic aspects of their activity.

Using a collaborative approach, over 200 community center registrants were directly involved in making art, and over a thousand persons saw it. It was my experience that participation from the instructors and participants was overall enthusiastic and motivated by curiosity and fun.

\section{Recommendations}

I believe that the following principles were important to the success of this residency.

From the onset, I clarified that the participants were the experts at the activity and that I would not be asking them to learn and perform new skills. We were going to use their games, their drills and exercises. I made every effort to be the least intrusive while observing and actually participating in the activity when appropriate. I made as little demand on center staff aiming to be as self-sufficient as possible. It was important to be able to adapt to the time limitations and cultural expectations of the different groups. I kept a flexible schedule as the schedule of classes changed during the year and some were in the evening. I attempted to use a multiplicity of media and places for display to reach different audiences and to establish a constant presence.

Several minor challenges arose and could be improved with more planning.

Work and storage space took time to be found. This should be negotiated before the project starts. The physical limitations of the building for displaying works could have been outlined at the onset, e.g., motion sensors influenced the type of hanging projects that could be displayed.

More communication with the center's board, staff and registrants would have been beneficial. Although circulated on the social media for the center, the project did not get sufficient attention through the network of the city art programming. More efforts could have been made to organize this with the city to maximize 
awareness of the general public with the project and accompanying expositions. Despite attempts there was no success in getting any of the works displayed in other community centers or city hall.

Getting the photographic and video consent from the parents remained an unresolved problem. Obtaining photograph waivers before classes started, particularly from the parents of the children would have allowed for different projects. The solution was to video mostly feet movements and take motion trail images (see Figures 3 and 4).

Only one instructor was persistent enough to get all the forms signed and identify the couple students whose parents did not want their children photographed. Getting the forms signed at registration would have been ideal but it would have required earlier planning in selecting the classes to be used.

All the videos and most of the images were shown on the internal monitor system infrequently. It depended on a staff remembering to put them on. A dedicated screen would have been useful. A website was dedicated to document the works and remains available at www.leichner.ca.

By the end of this residency, two instructors and a couple of registrants inquired about continuing the projects. Unfortunately, there were no funds to continue the projects. There was also no opportunity to show the works outside the center. This is a common problem with community-engaged projects. They underestimate the time required for the artist to become effective in the setting and understand its culture, particularly, as most are on a part time basis. It would be ideal if such projects could be designed from the onset to run for several years.

Project evaluation was limited by the experimental nature of the work, limited time and reluctance from staff to pursue registrants for it. This is another component that could be planned for before starting the project. However, it would have been most effective in a second year, when the opportunities and the means required could be identified from the onset. Nevertheless, an anonymous feedback survey was distributed to instructors and staff at the end of the residency. Fourteen out of 20 responded. All had noticed the art displays in the center. They rated it as having a moderate impact on the environment. Most had heard feedback from the participants, and it was very positive overall. Positive comments such as "Very engaging for all ages" and "it helped provide a sense of community” were made. Suggestions for improvement included better communications with staff and board and more organization before beginning such a project. A couple respondents did not see much benefit from the project. Getting feedback from actual participants through a survey was not possible.

\section{Conclusion}

Art and sport share many similarities in practice and purpose. Both connect us to our environment and to ourselves. Both are necessary for our individual and community wellbeing.

It was my experience that most participants in this recreational community centre readily engaged in an artistic expression of their sports and the public welcomed this. The interviews from participants left no doubt that those facilities like the Thompson Community Center are critical to healthy development of youth and the maintenance of wellbeing for participants of all ages and their community.

One major shortcoming of this project was its short time span. It seemed like this project stopped at the time when instructors and participants started to become influenced by it.

By the end of this residency, rather than looking for similarities or differences between art and sport, I became more aware that art is an integral component of all sports. This can also be said about heath care and education as well. It is the art that reaches us in an emotional, sometimes hard to explain way, whether we score a goal, watch gymnastics, or hear the laughter of children playing a game. 


\section{References}

Best, D. (1980). Art and sport. Journal of Aesthetic Education, 14(2), 69-80.

Bishop, C. (2018). Bring the noise, Tate Etc. 16: Summer 2009. Retrieved from https://www.tate.org.uk/context-comment/articles/bring-noise

Cordner, C. (1988). Differences between sport and art. Journal of the Philosophy of Sport, 15, 31-47.

Doyle, J. (2018). “Art versus sport”: Managing desire and the queer sport spectacle. XX.TRA. Retrieved from http://x-traonline.org/article/art-versus-sport-managing-desire-and-the-queer-sport-spectacle/2/

Helguera, P. (2011). Education for socially engaged art. New York: Jorge Pinto Books.

Kosiewicz, J. (2014). Sport and art: Differences and theatrical similarities. Physical Culture and Sport. Studies and Research, 61, 69-87.

Leichner, P. (2017). “SpART” event archive. Retrieved from http://www.leichner.ca/SpART.html

Leichner, P. (2019). Engaged art. Retrieved from http://www.leichner.ca/Curating/curating.html

Leichner, P., Lagarde, E., \& Lemaire, C. (2014). Windows to discover: A socially engaged art project on isolation in the community. Arts and Health, 69, 90-97.

National Organization for Arts in Health. (2017). Arts, health, and well-being in America, San Diego, CA. Retrieved from https://www.artsandhealth.org.au/app/uploads/2017/03/ACAH-2017-NOAH-National-Organisation-for-Arts-in-Health-USAWhite-Paper-Online-Edition.pdf

Tainio, M. (2015). Parallel worlds. Art and sport in contemporary culture. Helsinki: Aalto ARTS books. 